\title{
AENFERMAGEM E A CRIANÇA VÍTIMA DE VIOLÊNCIA SOB O OLHAR DE PATERSON \& ZDERAD
}

\author{
Simone Marchezan ${ }^{1}$, Carla Lizandra de Lima Ferreira², Hilda Maria de Freitas Medeiros ${ }^{3}$, Adriana Dall’ Asta Pereira ${ }^{4}$
}

\begin{abstract}
RESUMO: Estudo qualitativo-fenomenológico que objetivou desenvolver o cuidado de enfermagem à crianças vítimas de violência; refletir sobre o papel da enfermagem no cuidado às vítimas e retratar o reflexo social da violência contra a criança. Fizeram parte desta pesquisa quatro crianças, alunas de uma Escola Municipal de Santa Maria/RS. Os dados emergiram das atividades lúdicas, do diálogo vivido e da observação realizados em seis encontros, entre março e julho de 2008. Os dados foram registrados em diário de campo e após sua análise descritos em categorias significativas. Ao desenvolver o cuidado norteado pelas cinco fases do processo de enfermagem de Parterson \& Zderad foi possível identificar o significado da família na vida dessas crianças, a importância da enfermagem no bem-estar e estar-melhor das vítimas e a relevância do amparo social às famílias como uma das soluções para a problemática.
\end{abstract}

PALAVRAS-CHAVE: Criança; Violência; Teoria de enfermagem.

\section{NURSING AND THE CHILD VICTIM OF VIOLENCE UNDER PATERSON \& ZDERAD’S POINT OF VIEW}

\begin{abstract}
This is a phenomenological-qualitative study with the objective of caring for the child victim of violence, to reflect on the role of nursing on caring for these victims, and as well as to expose the social reflect of violence against children. Four students of Santa Maria Municipal School/RS participated on this research. Data were obtained through play activities, lived dialogue and observations during 6 meetings between March and July of 2008, were registered in a field journal, and the analyzed and subsequently described in significant categories. On caring by the guidance of the five phases of the nursing process by Paterson \& Zderad, we were able to identify the meaning of the family in these children's lives, the importance of nursing in the well being and being well of the victims and the relevance of the social support to the families as one of the solutions to the problem.
\end{abstract}

KEYWORDS: Child; Violence; Nursing theory.

\section{LA ENFERMERÍA Y EL NIÑO VÍCTIMA DE LA VIOLENCIA DESDE EL PUNTO DE VISTA DE PATERSON \& ZDERAD}

RESUMEN: Estudio cualitativo-fenomenológico que objetivó desarrollar el cuidado de enfermería a los niños víctimas de la violencia; reflexionar sobre el papel de enfermería en el cuidado de las víctimas y representar el reflejo social de la violencia contra el niño. Hicieron parte de esta investigación cuatro niñas, alumnas de una escuela municipal de Santa Maria / RS. Los datos surgieron de las actividades lúdicas, del diálogo vivido y de la observación, realizados en seis sesiones, entre marzo y julio de 2008. Los datos fueron registrados en el diario de campo y después de analizados, descritos en categorías significativas. Al desarrollar el cuidado guiado por las cinco fases del proceso de enfermería de Parterson \& Zderad fue posible identificar el significado de la familia en la vida de estos niños, la importancia de la enfermería en el bienestar y ser-mejor de las víctimas y la relevancia del amparo social a las familias como una de las soluciones para el problema.

PALABRAS CLAVE: Niño; Violencia; Teoría de enfermería.

${ }^{1}$ Enfermeira. Aluna da Especialização em Saúde Pública do Instituto de Pós-graduação e Extensão-IBPEX. Graduada pelo Centro Universitário Franciscano-UNIFRA. Membro do Grupo de Pesquisa Cuidado às Pessoas, Famílias e Sociedade-GEPES-UFSM-RS. ${ }^{2}$ Enfermeira. Mestre. Docente do UNIFRA. Membro do GEPES-UFSM/RS. Membro do Grupo Interdisciplinar de Pesquisa em Enfermagem e Saúde-GIPES-UNIFRA.

${ }^{3}$ Enfermeira. Mestre. Docente do Curso de Enfermagem do UNIFRA. Membro do GEPES-UFSM/RS. Membro do GIPES-UNIFRA. ${ }^{4}$ Enfermeira. Mestre. Docente do UNIFRA. Membro do GIPES-UNIFRA.

Autor correspondente:

Simone Marchezan

Rua Venâncio Aires, 1795 - 97010-003 - Santa Maria-RS.

Recebido: 29/08/08

E-mail: simonemarchezan@hotmail.com.

Aprovado: 20/12/08

Cogitare Enferm 2009 Jan/Mar; 14(1):44-51 


\section{INTRODUÇÃO}

A criança é um ser em construção, carregado de vida, criatividade e curiosidade. No entanto, é um ser indefeso, frágil que necessita de proteção, cuidado, afeto e vida familiar e comunitária harmoniosa para crescer e se desenvolver em potencial. Ela começou a ser percebida dessa maneira, a partir da reforma moral e religiosa, no século XVII e ganhou os moldes atuais com o advento da modernidade e o surgimento da escola. Até esta época, a criança era considerada um 'adulto em miniatura'. A infância passou, então, a ser estudada e a criança, a ser percebida como diferente do adulto. Surgem assim, novas concepções familiares em relação à criança e à infância ${ }^{(1)}$.

Embora a compreensão da relação do ser criança com a família tenha ganhado outra conotação ao longo dos anos, diante do risco da violência a infância continuou sendo violada. Apesar dos esforços de diferentes setores da sociedade, ainda persiste a ocorrência de violência contra a criança, a qual se manifesta nas formas física, sexual, psicológica e negligência ${ }^{(2)}$.

Dados da Organização das Nações UnidasONU enfatizam que o número de crianças entre 0 e 14 anos, no mundo, é de 1,82 bilhões, representando $28 \%$ da população mundial. Com o aumento da expectativa de vida e o gradual envelhecimento da população, a ONU prevê que, em 2050 a população mundial de crianças será de apenas 20\% do total, diminuindo nas regiões desenvolvidas e aumentando nos países pobres ou emergentes, nos quais hum bilhão de crianças vivem em condição de pobreza ${ }^{(3)}$.

Considerando esses fatos, há a ocorrência de crianças que vivem em situações críticas sendo duplamente vitimizadas, seja pela violência estrutural em que estão submetidas, sem acesso à saúde, educação, moradia, alimentação, emprego e lazer, ou pela violência que sofrem dentro do $\operatorname{lar}^{(4)}$.

As estatísticas apontam que, a maior parte dos abusos contra crianças são praticados dentro de casa, por pessoas próximas a criança, com quem mantém uma relação de confiança e silêncio, podendo ser familiares, parentes e vizinhos. Assim sendo, as seqüelas apresentadas pelas vítimas são difíceis de quantificar ${ }^{(5)}$. Uma vez que, a violência produzida por pessoas que a criança tem amor, interfere na construção da autoconfiança e da confiança nos outros, determinando para criança, uma situação de severa desproteção e vulnerabilidade ${ }^{(6)}$.

A violência quando perpetuada na vida da criança é mutilante não apenas física, mas psicologicamente e é gradual, ou seja, quanto mais tempo ela é perpetuada na vida da criança mais ela se agrava, deixando maior número de seqüelas. Ações no sentido de evitar ou remediar os efeitos futuros da violência devem ser desenvolvidas, envolvendo a escola, a comunidade, as instituições de saúde, cada cidadão e a enfermagem.

Considerando a crescente participação da enfermagem em diferentes espaços de promoção, proteção e recuperação da saúde das crianças como: escolas, nos Programas de Saúde da Família entre outros, é importante que estes profissionais estejam preparados para prestar assistência às crianças que sofrem violência. Portanto, este estudo tem como objetivo desenvolver o cuidado de enfermagem às crianças vítimas de violência seguindo os pressupostos básicos da teoria de Paterson \& Zderad ${ }^{(7)}$, refletir sobre o papel da enfermagem no cuidado às vítimas e retratar o reflexo social da violência contra a criança.

\section{CAMINHO METODOLÓGICO}

Este é um estudo qualitativo, do tipo fenomenológico constituído de uma prática existencial embasada nas cinco fases da Teoria Humanística de Enfermagem de Paterson \& Zderad ${ }^{(7)}$. Estas fases constituem-se em: $1^{\text {a }}$ - preparação da enfermeira para vir a conhecer; $2^{\mathrm{a}}$ - conhecimento intuitivo do outro na relação $E u$ - $T u^{(8)}$; $3^{\text {a }}$ - conhecimento científico do outro, por meio das reflexões, análises e conceituações ${ }^{(7)} ; 4^{a}$ sintetização complementar das realidades conhecidas, interpretando e classificando observando aspectos presentes ou ausentes ${ }^{(7)}$ e $5^{\text {a }}$ fase- ampliação do conhecimento dos múltiplos ao paradoxal. Trata-se da visão articulada da experiência que passa ser expressa em um todo coerente ${ }^{(9)}$.

$\mathrm{O}$ encontro existencial da enfermeira com a criança vítima de violência é descrito a seguir adaptado para o contexto do estudo.

\section{Preparação para o vir a conhecer a criança vítima de violência buscando o autoconhecimento}

Esta etapa da vivência correspondente a primeira fase da Teoria Humanística, foi dedicada à leitura, de livros, periódicos, artigos de revistas, manuais, dissertações e sites da internet que discutiam o tema violência assim como sobre a natureza do ser humano. Foi um processo de autoconhecimento e de 
reflexões a cerca do que os autores relatam sobre o universo infantil e a realidade das crianças que convivem com a violência.

\section{Conhecendo a criança vítima de violência intuitivamente}

Este momento da pesquisa compõe a segunda fase de Paterson \& Zderad ${ }^{(7)}$, momento de aproximação do local de estudo, uma Escola Municipal de Santa Maria/RS, localizada numa região do Município com índices de violência contra crianças e adolescentes de $32,6 \%^{(10)}$.

Fizeram parte deste estudo crianças integrantes de um projeto assistencial da escola que reunia alunos da $2^{\text {a }}$ e $3^{\text {a }}$ séries do ensino fundamental. Estes alunos permaneciam na escola em turno integral, recebiam alimentação, desenvolviam aulas de reforço, recreação, atividades extras e aulas de informática.

Foram desenvolvidos seis encontros em grupo com as crianças, com duração de uma hora cada, na escola entre os meses de março e julho de 2008 tendo como ambiente a sala de aula. Das 25 crianças inscritas no projeto, quatro participaram do estudo, três do sexo feminino e uma do sexo masculino. O critério de inclusão e exclusão foi apresentar alguns indicadores ${ }^{(1)}$ apontados pelos professores, pela observação da enfermeira que se preparou para o vir a conhecer, ou seja, pelo comportamento das crianças durante atividades, pela visualização de traumas físicos, e pelos relatos espontâneos das crianças. Os indicadores de violência são ${ }^{(1)}$ : terminologia inapropriada para a idade, conduta muito sexualizada, vestimenta inadequada ao clima, problemas físicos e/ou necessidades não atendidas, pouca atenção, comportamentos extremos hiper ou hipoativo, assume responsabilidades de adulto, problemas na aprendizagem, comportamentos de agressividade ou timidez, apresenta causas viáveis para suas lesões, faltas freqüentes, dificuldade na aprendizagem, dificuldade de concentração.

Os dados foram coletados sem roteiro préestabelecido, emergiram da prática do cuidado por meio da observação participante, do diálogo vivido entre enfermeira/criança e do significado que as crianças atribuíram aos seus desenhos, pinturas e colagens. No registro das informações, utilizou-se um diário de campo, no qual foram registradas percepções do pesquisador assim como, as reações, falas, gestos, participação e interesse das crianças nas atividades.

As informações coletadas se submeteram à análise de conteúdo temática, buscando conceitos abrangentes que possibilitassem a compreensão dos fenômenos captados na experiência ${ }^{(11)}$, mostrando em categorias alguns dos sentidos que o corpus textual permitiu construir. As categorias encontradas após a análise foram: As crianças revelam no brincar o mundo em que vivem. As crianças revelam relação/ vínculo com a família $X$ dia-a-dia com a violência. As crianças são seres sociais e revelam relações frente as novos hábitos de vida e de consumo.

Para atender à Resolução 196/96 ${ }^{(12)}$, que regulamenta a pesquisa com seres humanos, o processo de investigação teve início após o projeto ter sido aprovado pelo Comitê Técnico Científico do Centro Universitário Franciscano, CONEP: 1246, Protocolo: 312.2007.2 e autorizado pela Direção da Escola.

Mediante orientações do comitê o Termo de Consentimento Livre Esclarecido não foi assinado pelos responsáveis diretos pelas crianças e sim pela direção da escola, para preservar a integridade física das crianças e a do pesquisador uma vez que, se desconhece os agressores, podendo ser eles, o pai, a mãe, ou ambos assim como parentes próximos morando na casa com a criança. As suspeitas em nenhum momento da pesquisa foram reveladas às crianças, e nem induzido às mesmas a falarem sobre as situações de violência, uma vez que o objetivo principal da pesquisa era possibilitar por meio da aplicação da teoria um cuidado de enfermagem. Elas participaram dos encontros espontaneamente e não tinham restrições de sair da sala no momento que desejassem. Para preservar o anonimato as crianças foram identificadas no estudo com nomes de anjos, sendo assim: Muriel, Ariel, Aniel e Gabriel.

\section{ANALISANDO E REFLETINDO A VIVÊNCIA}

Depois de acompanhar a criança intuitivamente, conceituou-se essa experiência conforme o potencial humano da enfermeira, vivenciando a terceira fase da teoria de Paterson \& $\mathrm{Zderad}^{(7)}$. Foram feitas reflexões a cerca das experiências subjetivas com cada criança considerando realidades já conhecidas e analisadas, comparando-as e contrastando-as.

Muriel, nove anos, do sexo feminino, vítima de negligência e suspeita de violência sexual. Mora com o pai e mais duas irmãs, a mãe havia abandonado o lar. Apresentava higiene corporal e das vestes prejudicadas, vestes inapropriadas para época do ano, couro cabeludo e cabelos infestados por pediculose, lesões infeccionadas na região dos pés e tornozelos e 
manchas esbranquiçadas na região do rosto, pescoço e sobrancelhas sugestivas de micose. Isso configura negligência;

Descrita como a falta de responsabilidade, calor humano, interesse com as necessidades e manifestações da criança. [...] por ser comum, passa muitas vezes despercebida [...] podendo, na prática ser evidenciada pela falta de cuidado físico, expressa por sujidade, escabiose, pediculose e tungíase recorrentes ou não tratadas $[. . .]^{(2: 42)}$.

Nos encontros, Muriel era desconfiada, agressiva [com os colegas, irmã, e enfermeira], rebelde [se negava a participar das atividades e bagunçava as atividades dos demais colegas], isso dificultava a aproximação. Possuía sexualidade aguçada, demonstrada nas atitudes com os colegas meninos, nas vestes curtas e justas e nos indícios de manipulação da genitália [riscos de canetas e orifícios nesta região]. Esses comportamentos sexuais precoces para a idade indicam que a criança pode estar sendo abusada sexualmente ${ }^{(13)}$. O abuso sexual é uma realidade triste, que incluí carícias, manipulação da genitália, mamas, ânus, pornografia e exibicionismo, ato sexual com ou sem penetração, com ou sem violência e até o comércio do sexo ${ }^{(5)}$.

Com o passar do tempo, começou a gostar de desenhar, pintar e passou a comentar sobre as atividades que desenvolvia. Nos comentários de Muriel, foi observado que sua infância era vivenciada nos afazeres domésticos [relatava que era responsável por lavar a roupa, limpar a casa e cuidar da irmã menor quando não estava na aula], situação essa considerada negligência uma vez que a criança está assumindo responsabilidades incompatíveis com seu estágio de desenvolvimento ${ }^{(2)}$. A alegria de criança também foi observada, quando contava sobre os banhos de tanque com as irmãs. Percebia-se então neste momento um sorriso infantil, pois, “[...] ser criança é ser coração, é sorrir e chorar, é ser feliz”(14:27).

Ariel, irmã de Muriel, sete anos, sexo feminino, apresentava indicadores de negligência e violência sexual $^{(1)}$. Apresentava higiene corporal e das vestes prejudicadas, couro cabeludo e cabelos infestados por pediculose, vestia-se inapropriadamente para época do ano [desagasalhada e descalça]. Nos encontros, foi observada dificuldade de aceitação por parte de Muriel [disputava a atenção da professora e da enfermeira], tinha pudor excessivo em relação ao corpo, observado no gestual e na maneira como se referia a ele. Foi a participante mais carinhosa, falava pouco, era muito envergonhada, realizava todas as atividades, diferente da irmã, falava mais do pai e comentava que sentia falta da mãe. Segundo relato da professora, não conseguia concentrar-se na sala de aula e não copiava as lições. Essas dificuldades na escola podem ter como pano de fundo a violência sexual ${ }^{(2)}$.

Gabriel, sete anos, sexo masculino, suspeita de estar sendo vítima de violência sexual. Apresentava higiene corporal satisfatória, vestes limpas e apropriadas para época do ano e desenvolvimento pondero-estatural prejudicado. Mora com a avó materna e duas tias. Nos encontros, era agitado, por vezes prejudicando o rendimento do grupo, resistente às atividades, realizava brincadeiras agressivas com os/as colegas, por horas revoltado, tinha dificuldade de concentração. Seu linguajar e gestual, assim como as atitudes em relação aos colegas tinham conotação sexual muito avançada para idade.

Com o desenvolver das atividades, Gabriel, apresentou mudanças no comportamento, percebidas pela enfermeira e pela professora, relação aos demais colegas e durante as aulas e melhora na concentração. As atividades desenvolvidas nos encontros, assim como o diálogo vivido(7) e a motivação, ajudaram a criança a lidar com suas emoções e impulsos, observando então, o estar melhor ${ }^{(7)}$.

Aniel, oito anos, sexo feminino, com suspeita de maus tratos. Apresentava acuidade visual diminuída [não usava óculos], dificuldades na fala e na apreensão do conteúdo em sala de aula. Mora com a mãe e dois irmãos, o pai estava preso por tráfico de drogas. Era uma menina comportada, amorosa e desenvolvia todas as atividades com prazer. Falava pouco e seus olhos eram tristes. Possuía cicatrizes pelo corpo e escoriações na região torácicas, observadas por um vestuário descoberto, que atribuía a empurrões do irmão de seis anos. Estes fatos podem estar relacionados com a violência física, que ocorre quando uma pessoa, que está em relação de poder à criança, causa ou tenta causar dano não acidental, por meio do uso da força física ou de algum tipo de arma provocando ou não lesões externas, internas ou ambas( ${ }^{(15)}$.

Percebe-se que as crianças são vítimas também de tortura psicológica, que é a forma de violência mais freqüente e se manifesta nas atitudes autodestrutivas, timidez ou agressividade extrema e baixa auto-estima. Ela sempre acompanha as demais formas de violência( ${ }^{(2)}$.

Assim sendo, a partir da analise e reflexão do encontro existencial com a criança vítima de violência, faz-se a síntese dos outros conhecidos [quarta fase 
da Teoria Humanística], descrevendo a experiência em três categorias significativas. As categorias estão descritas a seguir:

\section{As crianças revelam no brincar o mundo em que vivem}

Ao longo da vivência como criança, o indivíduo se desenvolve como Ser-no-mundo, e é a partir da experiência e vivência do dia-a-dia que ele constrói seus ideais, isso requer ultrapassar as barreiras do Eu interior e do Mundo. Essa forma de relação com o mundo é evidenciada pela aflição sentida quando se escorrega e cai. Sente-se como se o chão fosse perdido, há, portanto, um sentimento de desapontamento, de perda do próprio mundo e do Eu simultaneamente ${ }^{(16)}$.

Quando, esta ligação entre o indivíduo e o mundo é um ser pelo qual têm amor, a simples falta de compreensão e de retribuição de afeto deste, gera um sentimento de perplexidade e aflição e ele se sente como se deixasse de ser a pessoa que imagina $\operatorname{ser}^{(16)}$.

Se existe dificuldade para os adultos em lidar com esses sentimentos de frustração e de perda, imagina-se como é para uma criança, um ser em desenvolvimento. Cada um precisa do seu "mundo" para saber onde está e quem é, logo a criança, principalmente. Na ocorrência da violência, ela perde o seu mundo, e passa a viver sentimentos contraditórios que tenta de alguma forma exteriorizá-los como um pedido de ajuda. Percebe-se estes sentimentos nas falas de Muriel e Gabriel.

Não deixa ela chegar perto de mim, não deixa [...] eu não quero ela aqui! (Muriel).

Eu vou pegar ele [...]. Vou quebrar ele a pau, tu vai ver! Não quero entrar [...] (Gabriel).

As crianças estão transferindo para as pessoas do seu convívio diário [colegas, professoras e enfermeira], a raiva e revolta que guardam dentro de si. A enfermagem deve estar atenta a esses indícios para ajudar sem fazer juízo de valor, pois a criança vítima de violência necessita ser respeitada e compreendida, porque foi ferida a sua integridade física e moral ${ }^{(5)}$.

A criança não é na sua essência violenta, mas a convivência com a violência acaba tornando-a violenta também. Isso se reflete nas brincadeiras, nos gestuais e linguajar agressivos e obscenos, repletos de significados de sua infância violada.

Eu quero, vou pegar ela de jeito, ela é muito gostosa!
[...] Vou te comer! Estou com muita vontade! Estou com muito tesão! Me espera [...] (Gabriel).

Portanto, as fala de Gabriel tem conotação sexual avançada para sua idade, que refletem o ambiente que a criança vive, e a reprodução da fala do adulto que emergiram nas brincadeiras dela nos encontros. Assim, nas brincadeiras, “[...] se expressam nossas múltiplas belezas, como também as mais sutis e grotescas mazelas humanas e sociais”(17:78).

A atividade lúdica é uma forma eficaz da enfermeira aproximar-se do universo dessas crianças. Portanto, o ato de brincar, desenhar, pintar permite à criança manifestar sentimentos, fantasias, desejos e experiências vividas. Assim como, exteriorizar as relações e papéis sociais internalizadas por ela, comunicar-se eficazmente com o adulto e fazer críticas ao meio e as relações familiares ${ }^{(5)}$.

\section{As crianças revelam relação/vínculo com a família $\mathrm{X}$ dia-a-dia com a violência}

A família faz parte da maior parte das vivências da criança. Quando a violência acontece dentro de casa, promovida por pessoas que a criança ama e têm como referência, seus mecanismos de defesa se fragilizam, se confundem e ela passa a viver o medo, a ansiedade, a angústia e silencia.

Quer ver como desenho um gurizinho? Meu gurizinho tá pelado! [...] só não quero falar quem é, não tenho vontade [...] é só um desenho (Muriel).

Tenho medo, ele está no hospital porque tá machucado [...]. Tem sangue [...] eles tão morto [...] (Aniel).

A fala de Muriel se relaciona a uma pessoa que é importante na sua vida, que ela desenhou com a maior dedicação na atividade, e da qual ela não revela a identidade. Já o relato de Aniel demonstra o medo que ela tem do hospital, da tortura e da morte.

Essas situações são uma constante na vida das vítimas, uma vez que, na maior parte das agressões as crianças e adolescentes não ultrapassam a barreira do silêncio imposta pelo agressor ${ }^{(18)}$. Isso acontece porque a maioria delas ocorre no âmbito do lar, e a vítima tem um vínculo afetivo com o agressor, além do medo e da revolta, ela tem esperança de que a violência não se repita. Assim, “[...] ela contará o fato 
a alguém quando perceber que esse comportamento do adulto não é normal, e sentir que esse alguém lhe inspira confiança e a segurança que não tem nos seus adultos agressores ${ }^{(13: 17) "}$.

Portanto, o cuidado à essa criança, vai além do cuidado técnico e científico, ele tem que ser baseado no vínculo, pois é ele quem vai determinar suas necessidades. Dessa forma, o afeto e a relação interpessoal são primordiais no cuidado à essas vítimas $^{(5)}$. Essa relação de vínculo e confiança permite ao cuidador saber a dimensão da violência no dia-adia dessas crianças. Portanto, a arte da enfermagem está na interação enfermeira com a criança, na qual o ser que cuida tem a possibilidade de auxiliar a si e ao outro a desenvolverem-se potencialmente, e obter, por meio da intersubjetividade do encontro do cuidado e de escolhas livres e responsáveis, o bem-estar e o estar melhor ${ }^{(7)}$.

A pobreza é um fator determinante às situações de violência. Convivendo com as desigualdades, a margem da sociedade, as famílias sobrevivem como podem, e muitas vezes a criança é sacrificada, não estudam, não vivenciam as brincadeiras de criança, para ajudar a família a enfrentar as dificuldades, e assim se afastam do seu universo infantil. Observa-se assim crianças com um tempo de infância muito reduzido, sem poder viver de acordo com suas necessidades e características ${ }^{(19)}$.

Não vou poder ir na aula de reforço, tenho que lavar roupa e minha irmã também não vai. Ela tem que ir buscar leite (Muriel).

Eu ajudo minha mãe limpar a casa e fazer comida porque ela trabalha no lixão e chega cansada [...] (Aniel).

O trabalho da criança, portanto; “[...] constitui um dos recursos que as famílias pobres utilizam para aumentar sua renda e como mecanismo social para enfrentar as emergências e situações de agravamento da subsistência ${ }^{(20: 237) "}$.

Essa condição subalterna de autonomia precocemente imposta não melhora a auto-estima e nem rompem com a pobreza e submissão ${ }^{(20)}$. Assim sendo, a criança assume responsabilidades inerentes a vida adulta e deixa as brincadeiras e a escola em segundo plano em sua vida contribuindo para a multiplicação da miséria.

$\mathrm{O}$ ato de brincar ajuda a criança a se adaptar ao mundo vivido, "[...] elas precisam de muito carinho e atenção [...] e vivenciar a infância por meio do brincar, do aprender, do viver, do sorrir, enfim do estar presente, do participar e do compartilhar com o

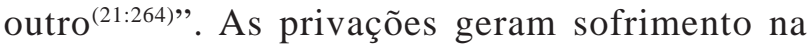
criança, pelas constantes necessidades materiais, percebe-se essas necessidades nas falas de Ariel.

Não tenho quarto prá mim, durmo com minhas irmãs [...]. Não penteio meu cabelo porque não tem pente lá em casa, nem espelho, nem geladeira [...]. Tomo banho no tanque [...] (Ariel).

Esta condição de escassez, de privações e de falta de perspectivas reduz a possibilidade de amar, de construir e de respeitar o outro ${ }^{(13)}$. "Na medida em que a vida à qual está submetido não o trata como homem, suas respostas tendem à rudeza em sua mera defesa da sobrevivência ${ }^{(13: 53)}$.

Assim sendo, a família deveria proporcionar todas as condições favoráveis para a criança se desenvolver em potencial, pois mesmo ela sendo negligente, violenta, ainda continua sendo o referencial dessas crianças. Para auxiliar a criança a superar estas adversidades a enfermeira tem que estar primeiramente disponível para ouvir.

Neste sentido Paterson \& Zderad, referem que a enfermagem relaciona-se à valorização do ser como ele é, suas potencialidades em ser mais, suas possibilidades em estar melhor, assim como as suas limitações em não ser. E dizem mais: "cada ser humano tem alguma coisa única para nos ensinar, se nós, pudermos ao menos ouvir"(22:427).

Este é meu pai, minha mãe e meus irmãos [...]. O pai voltou prá casa [...]. Estou muito contente [...] (Aniel).

Eu adoro festa de aniversário [...]. Está é a festa que minha mãe fez prá mim, tinha negrinho [doce típico da região], muita comida, cantaram os parabéns prá mim [...]. Foi um dia muito feliz para mim (Gabriel).

Olha o que fiz prá minha mãe, uma bolsa, fui eu quem pintou [...]. Domingo é dia dela, vou lá ver ela [...] (Muriel).

As falas das crianças expressam que, apesar de suas agruras existenciais, elas não perderam a 
capacidade de amar. Por mais adversas que sejam suas relações intra-familiares elas ficam felizes quando suas famílias estão reunidas, quando seus pais estão felizes, quando são lembradas nos seus aniversários ou quando, nas datas especiais, ganham presentes.

As crianças são seres sociais revelando relação frente aos novos hábitos de vida e de consumo

O ser humano é um ser-no-mundo; existe sempre em relação a algo ou alguém e compreende as suas experiências, vivendo num espaço e em determinado tempo ${ }^{(16)}$. Portanto, os valores sociais contemporâneos impõem às nossas crianças hábitos de vida e de consumo, muito além da sua realidade infantil.

Eu não assisto desenho [...]. Eu gosto de assistir aquela novela que tem o Juvenal Antena [...]. Gosto de ver a Alzira, aquela que dança [...] quero ser que nem ela [...] (Muriel).

Eu quero ser policial, dar tiro nos outros [...] acho que quero ser bandido, roubar, matar [...] ser importante [...] (Gabriel).

As colocações acima são resultados de padrões identificatórios globalizantes e apresentados como insígnias [imaginárias] se sucesso pelos meios de comunicação, para criar comportamentos e difundir valores de felicidade ${ }^{(23)}$. Portanto, a criança;

[...] em todos os segmentos sociais, é refém das contradições sociais [...]. Exige-se que tenha bom comportamento ao mesmo tempo em que entre seus instrumentos de lazer, games extremamente violentos; ela é envolta nos mais variados tipos de estimulação [...], informações da internet até a violência que preencheu todos os nossos espaços suburbanos; e como agravante, tem de se manter presa a valores que não lhe foram ensinados, mas que são exigidos no convívio social ${ }^{(24: 119)}$.

Assim sendo, a enfermeira durante o cuidado às crianças vitimizadas, deve superar qualquer projeto de criança idealizada, não buscando encontrar perfeições. Uma vez que, não existe uma criança universal, e sim crianças com existenciais plurais ${ }^{(17)}$.

Quando ficar grande quero ser professora [...] ajudar os outros a escrever [...] (Aniel).

Eu quero ser que nem a barbie pediatra, que cuida de criança [...] vou ser médica quero cuidar das crianças [...] (Muriel).
Sabe o que quero ser? Médica veterinária, cuidar dos animais, dos cachorros, dos cavalos daqui [...] (Ariel).

Nas falas, as crianças expressam seus sonhos, seus desejos que se relacionam com realidade onde estão inseridas. Demonstram vontade de mudar de vida, entretanto sem perder a capacidade de ser solidárias com seus semelhantes. Portanto, ela produz cultura, tem conhecimentos, tem competências e negar isso, é adiar direitos, possibilidades de criação, de expressão, de linguagens e de sonhos ${ }^{(17)}$. Importante então, a enfermeira dar possibilidades de expressão a criança vítima de violência, incentivá-la a ser mais, fortalecendo suas competências, seus pontos fortes.

\section{ALGUMAS REFLEXÔES SOBRE A VIVÊNCIA}

Esta etapa compõe a quinta fase de Paterson \& Zderad, na qual foi reunido todo conhecimento adquirido ao longo da prática existencial com a criança vítima de violência descrito em uma verdade única e pessoal.

Portanto, depois de vivenciar todo este processo verifica-se que a violência está intimamente relacionada à condição social das famílias. Uma sociedade que não protege suas crianças, que não tem políticas eficazes para atendê-las com dignidade e acaba por deixá-las a mercê de suas mazelas. Isso significa também não proporcionar às famílias condições favoráveis para ampará-las com uma casa decente, com alimentos à mesa nas refeições, educálas, dar afeto, amor e compreensão.

O estudo constatou que apesar dessas crianças sofrerem com a violência dentro de casa, elas amam suas famílias, e mantém forte vínculo afetivo com seus pais e irmãos. Refletindo o problema por este ângulo, ele ganha contornos dramáticos, e medidas urgentes devem ser tomadas, que amparem não só as crianças, mas também suas famílias para diminuir os agravos da violência infantil na nossa sociedade. Isso implica em acesso ao emprego, a saúde, a educação, alimentação, saneamento básico e a habitação.

A experiência mostrou que o cuidado de enfermagem baseado no vínculo, atenção e no diálogo, com o compartilhar de experiências, foram importantes para essas vítimas. O desenho, a pintura, recorte/ colagem foram recursos que auxiliaram no cuidado, pois possibilitaram uma melhor aproximação entre 0 mundo do adulto e o mundo infantil.

Assim sendo, desenvolvendo o cuidado norteado 
por Parterson \& Zderad foi possível identificar o significado da família na vida dessas crianças, a importância do cuidado de enfermagem no bem-estar e estar melhor das vítimas e a relevância do amparo social as famílias como uma das soluções para a problemática.

\section{REFERÊNCIAS}

1. Braun S. A violência sexual infantil na família: do silêncio a revelação do segredo. Porto Alegre: AGE; 2002.

2. Schwanck RH, Pauletti G, Zorzo JAT, Gomes VLO. A percepção de formandos de enfermagem acerca da violência contra a criança. Cogitare Enferm. 2005 Mai/ Ago; 10(2):41-6.

3. Cunha R. Percentual de crianças diminui, mas é grande o número das que vivem na pobreza [periódico na internet]. Com Ciência. 2005 [acesso em 2008 Jun 20] 72. Disponível em: http://www.comciencia.br/ reportagens/2005/12/04.shtml.

4. Ferreira CLL. A enfermagem cuidando de crianças vítimizados pelo abuso e exploração sexual [dissertação]. Florianópolis (SC): Universidade Federal de Santa Catarina; 2003.

5. Rocha PK. Crianças vítimas de violência: cuidar brincando. Blumenau: Nova Letra; 2006.

6. Assis SG, Avanci JQ, Santos NC, Malaquias JV, Oliveira RVC. Violencia e representação social na adolescência no Brasil [periódico na internet]. Rev Panam Salud Pública. 2004 [acesso em 2008 Jun 20] 16(1):43-51. Disponível em: www.scielosp.org.

7. Paterson J, Zderad LT. Enfermería Humanística. México: Limusa; 1979.

8. Buber M. Eu e Tu. Trad. de Newton Aquiles Von Zuben. $5^{a}$ ed. São Paulo: Moraes; 1977.

9. Praeger SG, Hogarth CR. Josephine E. Paterson e Loretta T. Zderad. In: George JB, organizador. Teoria de Enfermagem. Porto Alegre: Artes Médicas; 1993. p.24253.

10. Socal E, coordenadora. Pesquisa e Diagnóstico Sobre Crianças e Adolescentes em Situação de Risco Pessoal e Social em Santa Maria/RS: Construindo Cidadania. Santa Maria: Pallotti; 2003.

11. Moraes R. Uma tempestade de luz: a compreensão possibilitada pela análise textual discursiva. Ciência e Educação. 2003 Jan/Abr; 9(2):191-211.

12. Brasil. Ministério da saúde. Conselho Nacional de Saúde. Resolução nº 196/96. Diretrizes e normas regulamentadoras de pesquisa envolvendo seres humanos. Diário Oficial da União, Brasília, 16 out. 1996. Seção 1, p.21-82.

13. Ribeiro MM, Martins RB. Violência Doméstica Contra a Criança e o Adolescente: Realidade velada e desvelada no ambiente escolar. $1^{\text {a }}$ ed. Curitiba: Juruá; 2005.

14. Paula CC, Vernier ET, Padoin SMM. O ser-criança no Cuidado de Enfermagem. Enferm Atual. 2004 Set/Out; 4(23):23-28.

15. Brasil. Ministério da Justiça. Diretrizes nacionais para a política de atenção integral à infância e à adolescência. Brasília: CONANDA, 2001.

16. Forguieri YC. Psicologia Fenomenológica: Fundamentos, Método e Pesquisa. São Paulo: Pioneira Thonson Learning; 2004.

17. Debortoli JAO. Múltiplas Linguagens. In: Carvalho, A, Salles F, Guimarães M, organizadores. Desenvolvimento e Aprendizagem. Belo Horizonte: UFMG; 2002. p.73-96.

18. Maldonado MT. Os construtores da paz: Caminhos da prevenção da violência. $2^{\mathrm{a}}$ ed. São Paulo: Moderna; 2004.

19. Mamede MM. A criança na família e a família da criança. In: Correa LF, Correa ME, França OS, organizadores. Novos olhares dobre a gestão e a criança até os 3 anos: saúde perinatal, educação e desenvolvimento do bebê. Brasília: L.GE; 2002.p.481-93.

20. Azevedo MA. As políticas sociais e a violência doméstica contra crianças e adolescentes: um desafio recusado em São Paulo? In: Azevedo MA, Guerra VNA, organizadores. Infância e Violência Doméstica: fronteiras do conhecimento. $3^{\mathrm{a}}$ ed. São Paulo: Cortez; 2000. p. 228-230.

21. Medeiros HMF, Motta MGC. As repercussões de Viver em Casa de Apoio para a Criança com Aids. In: Paula CC, Padoin SMM, Schaurich D, organizadores. Aids: o que ainda há para ser dito? Santa Maria: UFSM; 2007. p.255-68.

22. Paula CC, Schaurich D, Padoin EMM, Crossetti MGO. O cuidado como encontro vivido e dialogado na teoria humanística de enfermagem de Paterson e Zderad. Acta Paul Enferm. 2004 Out/Dez;17(4):425-431.

23. Ceccarelli PR. Sexualidade e Consumo na TV. Psicol Clín. 2004 Dez;16(2):59-68.

24. Camon-Angerami VA. Suicídio Infantil: O Escarro Maior do Desespero Humano. In: Camon-Angerami VA, Valle ERM, Feijoo AMC, Maichin M, organizadores. O Atendimento Infantil na Ótica FenomenológicaExistencial. São Paulo: Pioneira Thonson Learning; 2004. p.109-45. 